\title{
Characterization of the decellularized ovine pericardium for skin tissue engineering
}

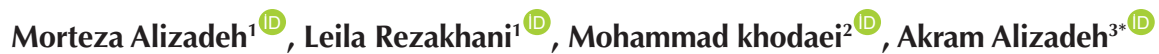 \\ ${ }^{1}$ Department of Tissue Engineering and Applied Cell Sciences, School of Advanced Technologies, Shahrekord University of \\ Medical Sciences, Shahrekord, Iran \\ 2Department of Materials Science and Engineering, Golpayegan University of Technology, Golpayegan, Iran \\ ${ }^{3}$ Cellular and Molecular Research Center, Basic Health Sciences Institute, Shahrekord University of Medical Sciences, \\ Shahrekord, Iran
}

*Corresponding Author: Akram Alizadeh, Mailing address: Rahmatieh, Cellular and Molecular Research Center, Shahrekord University of Medical Sciences, Shahrekord, Iran. Tel: +989128086698, 98-3833331471; Fax: 98-3833331471;

Email: alizadehbio@gmail.com

\begin{abstract}
Background and aims: Some biological scaffolds are used as appropriate skin substitutes, including decellularized amniotic membrane or dermis although the ovine pericardial tissue has not been characterized or used for skin tissue engineering. In this regard, this study focused on the decellularization and characterization of ovine pericardium for skin tissue engineering.

Materials and Methods: To this end, two different methods were used for decellularization, including safety data sheet (SDS) $1 \%(\operatorname{method} 1)$ and Triton X-100 1\% (method 2). In addition, histological examinations (H\&E staining), DNA content assay, scanning electron microscopy (SEM), MTT test using human adipose-derived mesenchymal stem cells, and tensile tests were conducted for sample characterization. Results: Based on the results, the DNA content showed significant DNA removing $(P<0.001)$ after decellularization with methods 1 and 2 in comparison to native tissues although the significance level between the two methods was $P=0.06$. In the SEM examination, cells were effectively removed while the extracellular matrix remained intact in both groups. Based on the results of the MTT test, the toxicity was not significant $(P=0.36)$. On the other hand, mechanical property assay revealed a higher value of Young's modulus in method 1 ( $34.12 \mathrm{MPa})$ compared to Method $2(32.57 \mathrm{MPa}$ ) and native tissues (30 MPa). Finally, the highest strain at the break point (approximately 0.6) belonged to the native sample.

Conclusion: In general, the ovine seems to be a good alternative for skin tissue engineering and regeneration since it is a post-slaughtering waste tissue has low thickness, is wide and spread, and easy to be decellularized with SDS 1\% and Triton X-100. Eventually, it has good properties for cell seeding based on the findings of our study and the capability of vascularization reported in the literature.

Keywords: Ovine pericardium, Acellular, Skin tissue engineering
\end{abstract}

Received: 13 March 2020, Accepted: 26 April 2020, ePublished: 29 December 2020

\section{Introduction}

Skin is the largest organ of the body and has many different functions. It is also the first protective barrier against the microorganisms, and the loss of this barrier could cause huge problems for the body, including infection and even death $(1,2)$. In addition, various factors may cause skin damage leading to tissue loss or harm to other organs, including burning, trauma, or chronic diseases (3-5). Nonetheless, there are some ways to deal with these problems and one of the most efficient ways in this regard is the use of tissue engineering approaches. Further, effective tissue repair by tissue engineering is significant and cost-effective because it could enhance the patient's quality of life while decreasing the length of therapy (6-8). The amniotic membrane is used as a biological dressing because it is cost-effective and preserve skin from losing heat and water. Furthermore, an important feature of the amniotic membrane is its capacity to provide relief from pain $(6,9,10)$. These kinds of grafts are widely employed for burned skin, skin wounds, and chronic ulcers (7). Decellularized skin itself is also used for the reconstruction of skin disorders such as the reconstruction of circumcised males (11). Moreover, the acellular dermal matrix has been applied for breast reconstruction and has grown well in the last decades. AlloDerm ${ }^{\circledast}$ is an acellular trademark human matrix, which was obtained from cadavers and used for breast reconstruction. For example, Zammit et al utilized the meshed form of this matrix in their study (12).

So far, bovine pericardium has been introduced as an ideal material for regenerating and managing the critical disorders of heart disease, including heart valve defects, ventricular septal disorders, and aortic annulus root

C 2020 The Author(s); Published by Shahrekord University of Medical Sciences. This is an open-access article distributed under the terms of the Creative Commons Attribution License (http://creativecommons.org/licenses/by/4.0), which permits unrestricted use, distribution, and reproduction in any medium, provided the original work is properly cited. 
infections (13). Pericardium contains three layers of serosa, fibrosa, and the epipericardial connective tissue. The serosa layer consists of mesothelial cells and submesothelial space. Additionally, the fibrosa layer contains collagen and elastic fibers, and the third layer encompasses collagen (14). The dermis part in the skin is full of vessels thus vascularization is highly important because of the nutrient and oxygen transport to the cells. Suturability is considered as one of the important facts of the wound dressing product. One study assessed the suturability of the ovine pericardium was assessed by the fabrication of pericardium tubes in a study (15).

In another study, the ovine pericardia were used for the reconstruction of dura mater $(16,17)$, and the bovine pericardium was applied in hernia and abdominal wall reconstruction (18). Veritas Collagen Matrix ${ }^{\circledR}$, as a type of commercial scaffold, is made of bovine pericardium for the reconstruction and regeneration of ventricles and pelvic defects (19). Likewise, the decellularized bovine pericardium is employed as duramaters in nerve surgeries (20). In a similar study, the porcine pericardium was used as prosthetic valves and it was shown that the decellularized tissue has some benefits such as accepting host-derived cells, enhanced endotelization, and being non-irritant for the immune system for a long term (21). In addition, Mogaldea et al studied the mechanical properties of the ovine pericardium (15). It should be noted that ovine pericardium is also one of the most wasteful animal by-products in Islamic nations. It appears that ovine pericardium could be used as a reliable product for skin tissue engineering because of its widespread and successful application in the medical field. Considering the above-mentioned explanations, the aim of this study was to decellularize and characterize the ovine pericardium tissue with two different methods, and finally, evaluate its possible application in skin tissue engineering for the first time.

\section{Materials and Methods}

\section{Preparation of ovine pericardium}

Based on the aim of the study, one and half-year-old male ovine of native Charmahal va Bakhtiari breed were selected from a slaughterhouse in Shahrekord, Iran and the pericardia were collected after sacrificing. Then, the adipose tissue was removed, the left part of the pericardia was put in a glass bottle containing $1000 \mathrm{cc}$, phosphatebuffered saline (PBS), and finally, transferred to the laboratory.

\section{Labeling of samples}

Three groups were included in this research:

A. The native tissues as the control group;

B. Method 1: Tissue decellularization with a safety data sheet (SDS, Biochem) 1\%;

C. Method 2: Tissue decellularization with Triton X-100
(Bio BASIC CANADA Lot: 1405NBXD10D) 1\%.

\section{Decellularization methods}

For the decellularization method 1, all samples were placed in roller bottles (Incubator GFL-7610) and incubated in SDS 1\% (Biochem CAS: $151-21-3$ ) at $40{ }^{\circ} \mathrm{C}$ for 24 hours, and the detergent was changed every 12 hours. Further, all samples were washed in distilled water (DW) at $4{ }^{\circ} \mathrm{C}$ for 12 hours and then washed again for 24 hours by DW that was changed every 8 hours. Regarding decellularization in method 2, all the samples were placed in roller bottles (Incubator GFL-7610) and incubated in Triton (X-100) $1 \%$ (Bio BASIC CANADA Lot: 1405 NBXD10D) at $40^{\circ} \mathrm{C}$ for 24 hours, the detergent was altered every 12 hours. Eventually, all the samples were washed in DW at $4{ }^{\circ} \mathrm{C}$ for 12 hours and then washed again for 24 hours by DW which was changed every 8 hours (13).

\section{Thickness of fresh ovine pericardium before and after decellularization}

A caliper (Shoka Gulf, China) was used to estimate the thickness of fresh samples.

\section{Histological examination}

All the samples were fixed in paraformaldehyde $4 \%$ for 24 hours (Merck CAS 30525-89-4) and processed by a tissue processor in four phases.

A. Dehydration: The samples were trimmed and dehydrated with ethanol in order to be prepared for wax penetration with ascending ethanol series.

B. Clearing: Since ethanol and wax are immiscible, xylene was used to cover this obstacle.

C. Wax infiltration: Paraffin at $60{ }^{\circ} \mathrm{C}$ was infiltrated into the tissue and then allowed to cool down to $20^{\circ} \mathrm{C}$.

D. Finally, the samples were blocked by wax and formed into a "block" (22).

Next, the blocks were sliced by a microtome at 5-7 $\mu \mathrm{m}$ (Leitz 1512) and stained with the hematoxylin and eosin (H\&E) staining for morphological assessment of the pericardia. Hematoxylin is a blue-purple color and changes nucleic acids to purple and eosin stains the extracellular matrix to pink (23).

\section{DNA content assay using Hoechst 33258}

Hoechst 33258 was applied to evaluate the remaining DNA in the decellularized tissue. First, the Hoechst staining (Sigma Aldrich, USA) was prepared by the dilution of the stock 1:5000 (1 mg/mL concentration). Furthermore, specimens were processed by a tissue processor, were blocked in paraffin, and then cut by a microtome at 5-7 $\mu \mathrm{m}$ (Leitz 1512). After deparaffinization in a $60^{\circ} \mathrm{C}$ incubator (Memert), the samples were washed in PBS and stained for 30 seconds, and then examined with a Dako fluorescent microscope (24). Eventually, the ImageJ software (version 1.51) was used to measure DNA 
intensity.

\section{Scanning electron microscopy (SEM) observation}

For SEM observation, the samples were cut in $0.5 \times 0.5$ $\mathrm{cm}$, fixed in paraformaldehyde $4 \%$, and freeze-dried for 1 hour. Next, the cross-section and surface of the samples were examined with TESCAN VEGA3, and the ImageJ software was utilized to measure tissue thickness (25).

\section{Isolation of human adipose-derived mesenchymal stem cells (hAD-MSCs)}

The human adipose tissue of the inguinal section was harvested from 15 hernias patients. The adipose tissues were then transferred to the laboratory, washed in PBS for three times, cut to $3 \mathrm{~mm}$, and digested with collagenase I at $37^{\circ} \mathrm{C}$. Thereafter, the cell suspension was neutralized with DMEM (Bioidea) + 10\% FBS (Gibco) and centrifuged at $1200 \mathrm{rpm}$ for 5 minutes. Next, the supernatant was discarded and the cells were transferred to the culture flask and incubated with DMEM $+10 \%$ FBS $+1 \%$ pen-strep medium in a culture incubator (Memert). The cells were used for the 3-(4,5-dimethylthiazol-2-yl)-2,5-diphenyl tetrasodium bromide (MTT) assay and cell culture on scaffolds after 3 passages (26).

\section{Viability test (MTT assay)}

The MTT test at 48 and 72 hours (based on the tetrazolium salt broke down by living cells with mitochondrial succinate dehydrogenase) was applied for viability assay $(27,28)$. Then, the succinate dehydrogenase of live cells broke down the tetrazolium and converted it to insoluble purple crystals. Moreover, $1 \times 10^{5} \mathrm{hAD}-\mathrm{MSCs}$ were seeded into a 24-well (in each well) plate, and 900 $\mu \mathrm{L}$ of the DMEM cell culture medium (containing 10\% FBS (Gibco, 1\% pen-strep) was added, and the plate was incubated in a humidified condition at $37^{\circ} \mathrm{C}$ and $5 \%$ of $\mathrm{CO}_{2}$ for 24 hours. Then, the samples of pericardia were put inside the wells containing the cells, and the toxicity test was conducted at 48 and 72 hours. Next, the samples were taken away and the supernatant was removed at each time point. Then, $100 \mu \mathrm{L}$ of the MTT solution $(5 \mathrm{mg} /$ $\mathrm{mL}$ ) was added to each well to reach a final $0.5 \mathrm{mg} / \mathrm{mL}$ concentration. Then the well was incubated for 4 hours. Additionally, the MTT solution was removed and $200 \mu \mathrm{L}$ of DMSO was added to each well and incubated for 30 minutes. Finally, the solution of each well was transferred to a 96-well plate, and an ELISA reader (Stat Fax 2100, USA) was used to determine the absorbance of each sample at 570-630 $\mathrm{nm}$. The cell survival percentage was also calculated for each concentration (29).

\section{Cell attachment assay}

After decellularization by both methods, the tissues were cut to $1 \times 1 \mathrm{~cm}$ and washed by PBS $+1 \%$ pen-strep for one hour, and then the scaffolds $(n=3)$ were put in a 48 -well plate and exposed to a UV light for 20 minutes. Next, 50000 hAD-MSCs with a DMEM + 10\% FBS + 1\% penstrep medium were added to each well. Eventually, the attached cells and their morphology were observed after 48 hours using the SEM.

\section{Mechanical characterization}

The tensile test was performed to evaluate the mechanical properties of the decellularized tissues. Then, the samples were cut to $15 \mathrm{~mm}$ in width and $40 \mathrm{~mm}$ in height and tested by a tensile testing machine (SANTAM, Universal Test Machine, STM 1, Iran) at a crosshead speed of 10 $\mathrm{mm} / \mathrm{minute}$, and the load cell capacity was $60 \mathrm{~N}(30)$.

\section{Statistical analysis}

All experiments were conducted in triplicate and the mean was calculated as well. One-way ANOVA and Tukey post hoc tests were used for data analysis by SPSS software, version 23. $P$ values of lower than $0.05(P \leq 0.05)$ were considered statistically significant and were shown with a * symbol $\left({ }^{*} P \leq 0.05,{ }^{* *} P \leq 0.01,{ }^{* * *} P \leq 0.001\right)$.

Results

Gross characteristics and thickness of the fresh ovine pericardium before and after decellularization

The pericardium was covered with various fats and vessels before processing and excess tissues were removed mechanically. After processing and decellularization, the thickness of the decellularized pericardia with a caliper was $400 \pm 45$ and $325 \pm 15 \mu \mathrm{m}$ for methods 1 and 2 , respectively, and the native tissue was approximately $450 \pm 55$. In addition, the color of the tissues after decellularization was similar in both methods although using method 1 made the tissue more slippery compared to method 2 (Figure 1).

\section{Hematoxylin and eosin staining}

In the $\mathrm{H}$ and $\mathrm{E}$ examination of the native tissue, the cells and nuclei are intact. Further, the collagen bundle and fibrils are merged together and have a pink color (Figure $2 \mathrm{~A})$. In method 1 , cells were removed but the collagen bundle and fibrils were not scattered based on the results of light microscopic imaging (Figure 2B). Furthermore, the cells were removed perfectly and the collagen bundles remained in method 2 (Figure 2C). Accordingly, no
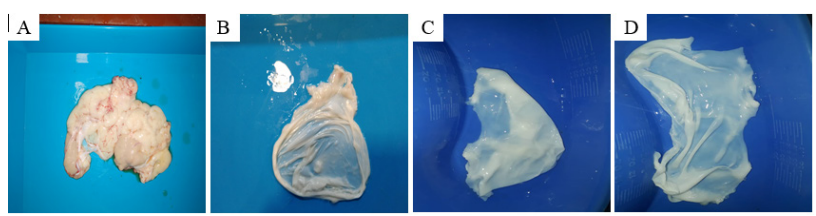

Figure 1. Fat containing pericardium (A), pericardium after fat removal (B), method 1 (SDS 1\%) including decellularized pericardium (C), and method 2 (Triton 1\%) including decellularized pericardium (D). 
significant changes were observed by light microscopic imaging in the two methods.

\section{DNA content assay using Hoechst 33258}

Hoechst staining was performed for native and decellularized tissues. The nuclei of the cells in the native tissue were stained by Hoechst 33258 (Figure 3A) constant and glowing blue. In the decellularized tissue by method 1 (Figure 3B), all samples were dark showing that the decellularization method removed all DNA perfectly. Figure 3C shows nuclear removal after decellularization with method 2. Microscopic studies revealed that both methods were successful in cell and DNA removal. Moreover, data analysis by measuring color intensity with image $\mathrm{j}$ software demonstrated that DNA concentration decreased close to $96 \%$ in method 1compared to the native tissue. Additionally, $90 \%$ of the DNA was removed using method 2. Based on the statistical analysis (Figure 4), the differences of the native tissue with methods 1 and 2 were significant $(P<0.001)$, respectively, while differences between methods 1 and 2 were not significant $(P=0.06)$.

\section{SEM observations}

The SEM observation of the native tissue represented that the collagens of native samples are highly dense and impacted (surface image Figure $5 \mathrm{~A}_{1}$ and cross-section Figure $5 \mathrm{~A}_{2}$ ). Imaging the surface and cross-section of the decellularized tissue samples with method 1 (SDS $1 \%$ ) showed that collagen fibers are extremely loose, and the thickness of the cross-section was higher compared to method $2\left(P=0.0236\right.$, surface image Figure $5 B_{1}$ and cross-section Figure $5 \mathrm{~B}_{2}$ ). In addition, there were no cells between the fibers. Further, the presence of collagen fibers was clear in the surface of samples treated by method 2 (Triton $1 \%$, surface image Figure $5 \mathrm{C}_{1}$ and cross-section Figure $5 \mathrm{C}_{2}$ ), and cross-section images demonstrated the
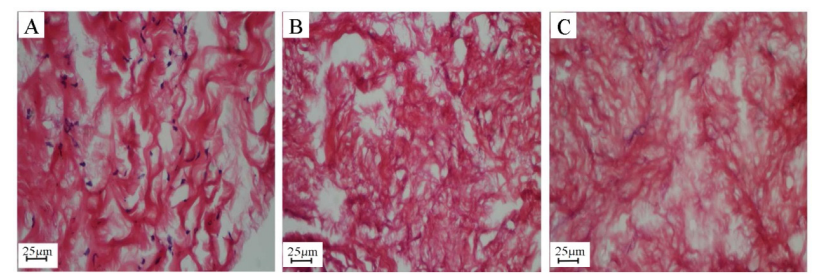

Figure 2. $\mathrm{H}$ \& E staining of samples.

Note. H\&E: Histological examination; Native (A), method 1 (B), and method 2 (C).
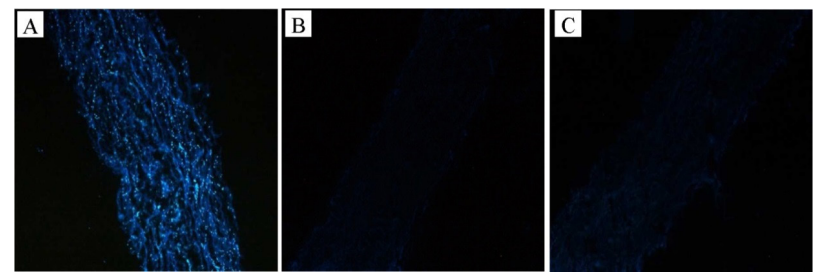

Figure 3. Hoechst 33258 staining for DNA debris assay. Note. Native (A), method 1 (B), and method 2 (C)

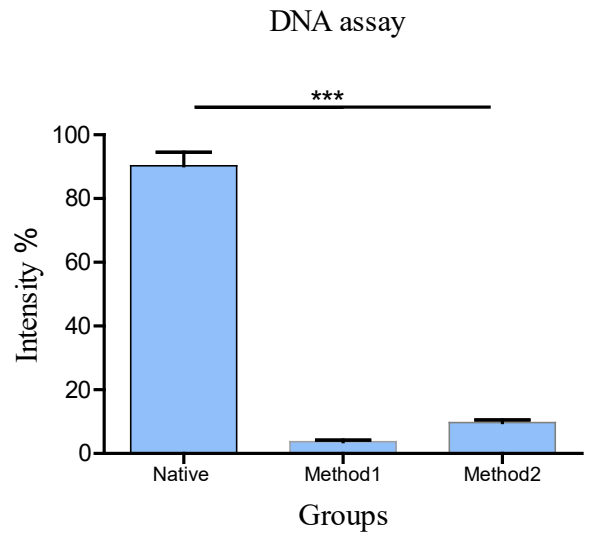

Figure 4. DNA content assay using Hoechst 33258 staining for DNA debris assay.
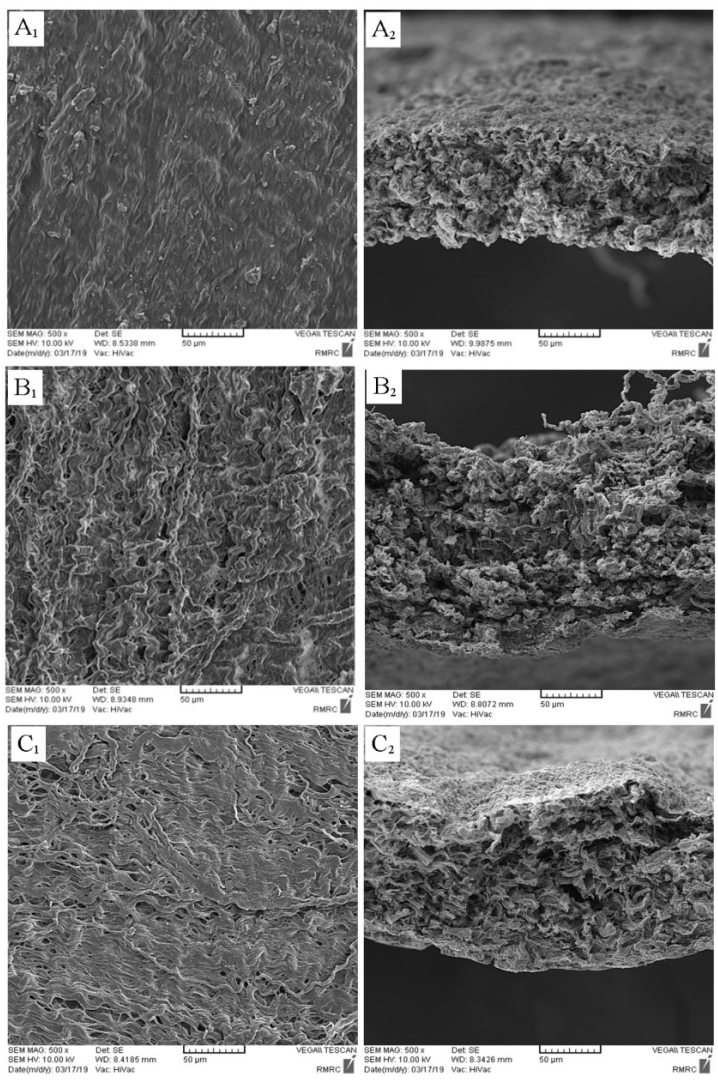

Figure 5. SEM micrographs of native and decellularized tissues. Note. SEM: Scanning electron microscopy; Surface and crosssection $\left(A_{1}, A_{2}, B_{1}, B_{2}, C_{1}\right.$ and $C_{2}$ display the surface and crosssection of native, method 1 , and method 2 , respectively).

lower thickness of these samples compared to method 1 . Furthermore, no cells were observed inside the samples. The SEM assessment revealed that the samples of method 2 are thinner compared to those of method 1 (Figure 6).

\section{Viability test (MTT assay)}

Figure 7 illustrates the results of viable cells next to decellularized tissue samples after 48 and 72 hours of cell culture in terms of optical density and cell viability with respect to control. The obtained results from the MTT 


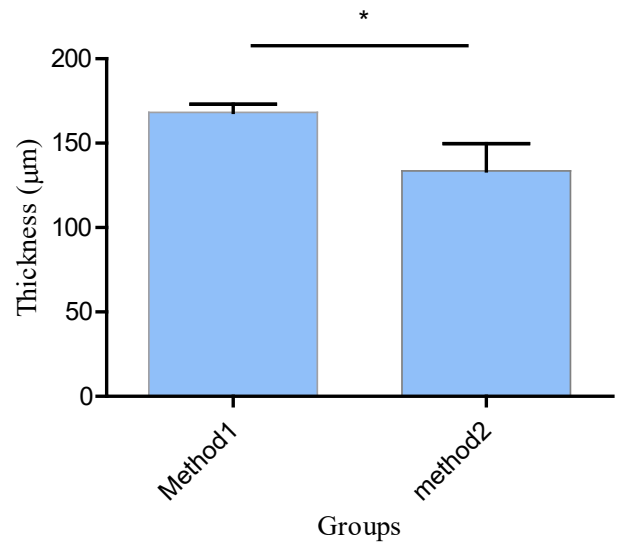

Figure 6. The thickness of the decellularized tissue in the SEM crosssection by both methods.

Note. SEM: Scanning electron microscopy.

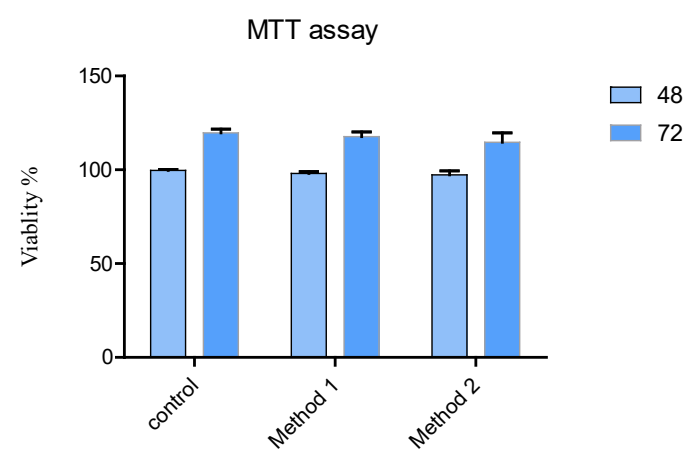

Figure 7. The viability test results for methods 1 and 2 After 48 and 72 hours.

assay demonstrated no toxicity of both methods compared to the control group for AD-MSCs after 48 and 72 hours of incubation $(P \geq 0.05)$. Although the cell viability of method 1 was slightly higher than that of method 2 , this increase was not statistically significant. More precisely, the viability of both methods was close to the control. In 48hour samples, the $P$-value was $0.36,0.17,0.83$ in nativemethod 1 =, native-method 2 , and method 1 -method 2 inter-group comparisons, respectively. Moreover, it was $0.77,0.26$, and 20.57 in native-method 1 , native-method 2, and method 1-method 2 inter-group comparisons among 72-hour samples.

\section{Cell attachment}

Based on Figures 8A and 8B, spindle-shaped hAD-MSCs on decellularized tissues were regularly dispersed and attached in both groups. In method 1 , the cells are wide and spread (Figure 8A) while they are compact and smaller in method 2 (Figure 8B).

\section{Tensile test}

The comparison of tensile tests between the two groups using Young's modulus showed the highest and lowest values for method 1 (SDS 1\%) and the native tissue, respectively (Figure 9). Additionally, the changes were significant between the native tissue and both groups ( $P=0.0006$ for SDS $1 \%$-treated and $P \leq 0.0070$ for Triton 1\%-treated). Based on the findings, no statistically significant differences were detected between Young's modulus of methods 1 and 2 , and the $P$ value was 0.0628 . The highest strain at the break point (approximately 0.6) belonged to native samples indicating the highest elasticity. Additionally, method 1 represented the lowest value. The Young's modulus of each group is provided in Table 1.

\section{Discussion}

The aim of this research was to characterize the decellularized ovine pericardium as an optimal decellularized scaffold for regenerating skin wounds, followed by comparing two methods in terms of decellularization. Sheep and goats are the most widely used food animals in Islamic countries. Although the inner parts of the sacrificed animals are disposed and are not used anymore, some parts such as pericardium could be applied for tissue engineering applications.

In this study, the thickness of the fresh native pericard was about $450 \mu \mathrm{m}$ and changed to about 325-400 $\mu \mathrm{m}$ after decellularization. In addition, Mogaldea et al showed that the thickness of ovine pericardium is about $276 \mu \mathrm{m}$ (15) and Parízek et al reported that the thickness of the ovine pericardium ranged from 70 to $130 \mu \mathrm{m}$ (17). It appears to be due to the difference in thickness with the results of Mogaldea et al and other scholars, depending on the breed of animal and the age. In addition, the thickness of the
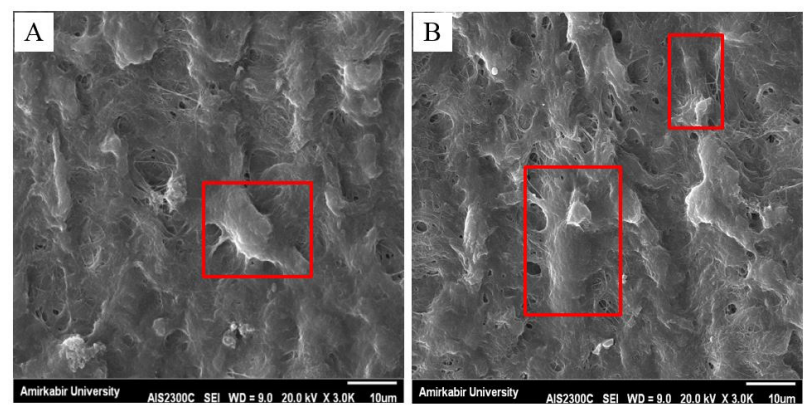

Figure 8. The SEM micrographs of cells attached in decellularized tissues by methods 1 (A) and 2 (B).

Note. SEM: Scanning electron microscopy.

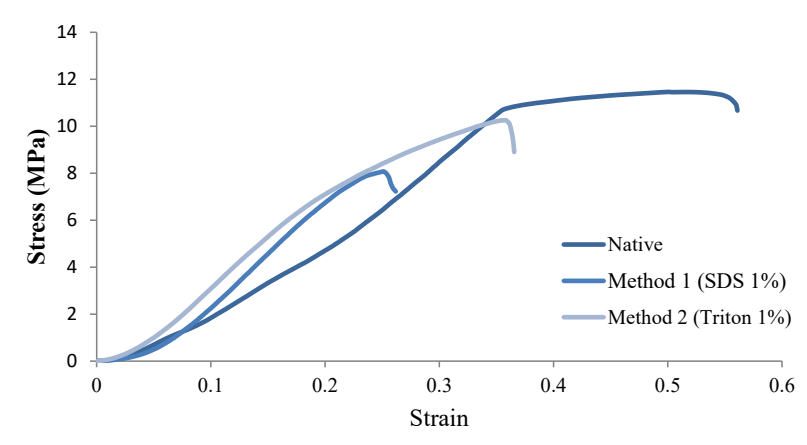

Figure 9. Stress-strain curves for the decellularized tissue in native, method 1 and method 2 groups. 
Table 1. Young's modulus of control and decellularized tissues

\begin{tabular}{lccc}
\hline Groups & Native & Method 1 & Method 2 \\
\hline Young's modulus $(\mathrm{MPa})$ & $30 \pm .7$ & $34.12 \pm .44$ & $32.57 \pm .9$ \\
\hline
\end{tabular}

native tissue after SEM treatment changed significantly probably due to the water vaporization of the cells after freeze-drying, which has broken down and collapsed the structure of native samples. The following reasons persuade the authors to suggest this tissue as a scaffold for skin tissue engineering. Based on the results of a study, the thickness of the in-vivo skin and the dermis were was 800-1000 $\mu \mathrm{m}$ and $600-800 \mu \mathrm{m}$, respectively (31). Further, the first report for skin transplantation using fetal membranes as the surgical graft was revealed by Davis in 1910, and since then the amniotic membrane has been used and expanded for these kinds of surgeries (32). The thickness of the normal amniotic membrane is $20-500 \mu \mathrm{m}$ (33). Wilshaw et al reported the thickness of the decellularized amniotic membrane as $146 \mu \mathrm{m}$ (34). Accordingly, the thickness of the ovine pericardium is in the middle thickness of the amniotic membrane (20-500). Thus, it could be a good candidate for skin regeneration in tissue engineering and regeneration medicine because this thickness can meet the basic needs of alternative skin. Furthermore, another study on vascularization in pericardial decellularized tissues demonstrated that vascularization can occur in these types of scaffolds (35).

The $\mathrm{H} \& \mathrm{E}$ staining is one of the gold standards for evaluating histological characteristics. The H\&E examination was also used in the present study and it was shown that the cells were well removed and the extracellular matrix was perfectly maintained in both SDS and triton methods. Similarly, Mogaldea et al used the H $\&$ E staining used for the examination of decellularized pericardia and represented that the combination of SDS and sodium deoxycholate (SDC) was successful in cell removal (15).

Hoechst staining was applied to successfully recognize decellularization methods because this analysis could show the DNA debris sharply in tissue microscopic sections (24). In our study, the Hoechst staining was used to estimate the remaining DNA in both methods, and the DNA content was measured by ImageJ. Both methods significantly reduced DNA content compared to the native tissue. The DNA removal in method 1 was more compared to method 2 due to the anionic properties of the SDS.

To the best of our knowledge, the present study was the first one to examine the ovine native and decellularized pericardium using SEM imaging. The results of our study confirmed that the thickness of the scaffolds changed by decellularization methods and the differences were significant. However, Mogaldea et al reported that there were no differences between the thickness of native and decellularized samples (15). It seems that this is the result of decellularization methods because the above-mentioned study used a combination of two detergents (i.e., SDS + SDC) and the concentration of each detergent was $0.05 \%$. Contrarily, in our study, detergents were not only used separately in two samples but also the concentration of the detergent was $1 \%$. SEM surface imaging showed differences between the SDS and triton. It seems that the SDS sample, unlike the triton, is highly bloated and collagen fibers open up more.

In the study by Gholipourmalekabadi et al on the amniotic membrane, the MTT assay demonstrated that the decellularized amniotic membrane had no negative effect on cell growth and activity (36). In our study, the ovine decellularized tissue had no negative and toxic effects on AD-MSCs. As far as the decellularized amniotic membrane was concerned, it was used as a wound dressing, and then the ovine decellularized scaffold would also propose as a material for this type of target.

SEM imaging from the surface represented some differences between the two methods. The dispersion of the cells in method 2 was less compared to method 1 apparently due to detergent differences. SDS is an anionic detergent, but Triton X-100 is a non-anionic detergent. It appears when the tissue is decellularized with anionic detergent, the surface of the decellularized tissue changes in a way that disperses the cells in a regular system. Triton X-100 disrupts lipid-lipid and lipid-protein interactions while leaving protein-protein interactions intact but SDS solubilizes cytoplasmic and nuclear cellular membranes and tends to denature proteins (37).

The static tensile test was first done at ovine pericardia, but surprisingly, high SDS and triton sample modulus were obtained in this study. In another study, we investigated the static tensile test on bovine pericards although the modulus decreased in all samples after decellularization compared to the native sample (38) while it completely contrived in this study. It seems that the detergent makes some changes to the matrix of the scaffolds and makes them more brittle. Therefore, the elasticity of the scaffolds decreased and the modulus increased accordingly. In addition, the thickness of the ovine pericardium was about 2 times less than the bovine pericardium. It appears that the detergent may have penetrated more into the ovine pericardium tissue in comparison to the bovine pericardium so that the molecular structure may have changed in the ovine pericardium and made it brittle.

\section{Conclusion}

The ovine pericardia have some characteristics such as the post-slaughtering waste tissue, low thickness, wide and spread, and good properties for cell seeding, based on the finding of our study, as well as the capability of vascularization, which was previously reported in the literature, and a possibility to be easily decellularized using different detergents (SDS and Triton X-100). Accordingly, 
it seems to be good advice for skin tissue engineering and regeneration.

\section{Conflict of Interests}

There is no conflict of interests in this study.

\section{Ethical Approval}

The study protocol was approved by the Research Ethics Committee of Shahrekord University of Medical Sciences (IR.SKUMS. REC.1397.170).

\section{Authors Contribution}

MA, Writing all of the article and sample collection and analysing of the sections. LR, writing Mtt section and analysing of this parts and editing of all section. $\mathrm{Mk}$, analysing the mechanical characteristics section and writing of the result in this part.AA, Supervise the entire set of samples and experiments and general editing of the text of the report and writing of it.

\section{Funding/Support}

This project financially supported by Shahrekord University of Medical Sciences (No. 2818).

\section{Acknowledgments}

This project was financially supported by Shahrekord University of Medical Sciences (No. 2818).

\section{References}

1. Lai-Cheong JE, McGrath JA. Structure and function of skin, hair and nails. Medicine. 2009;37(5):223-6. doi: 10.1016/j. mpmed.2009.03.002.

2. $\mathrm{Xu} \mathrm{H}$, Timares L, Elmets CA. 19 - Host defenses in skin. In: Rich RR, Fleisher TA, Shearer WT, Schroeder HW, Frew AJ, Weyand CM, eds. Clinical Immunology. 5th ed. London: Elsevier; 2019. p. 273-83.e1. doi: 10.1016/b978-0-70206896-6.00019-3.

3. Paul W, Sharma CP. Chitosan and alginate wound dressings: a short review. Trends Biomater Artif Organs. 2004;18(1):18-23.

4. Magnani ND, Muresan XM, Belmonte G, Cervellati F, Sticozzi C, Pecorelli A, et al. Skin damage mechanisms related to airborne particulate matter exposure. Toxicol Sci. 2016;149(1):227-36. doi: 10.1093/toxsci/kfv230.

5. Xie H, Chen X, Shen X, HeY, Chen W, Luo Q, et al. Preparation of chitosan-collagen-alginate composite dressing and its promoting effects on wound healing. Int J Biol Macromol. 2018;107(Pt A):93-104. doi: 10.1016/j.ijbiomac.2017.08.142.

6. Mohebichamkhorami F, Alizadeh A. Skin substitutes; an updated review of products from year 1980 to 2017. Appl Biotechnol Rep. 2017;4(3):615-23.

7. Ion L, Ionascu I, de Joz CG, Cerrada I, Birtoiu A, Huguet E. Human amniotic membrane transplantation in the treatment of feline corneal sequestrum: preliminary results. AgroLife Sci J. 2016;5(1):91-8.

8. Cheng X. Biomaterials for tendon/ligament and skin regeneration. In: Dobrzański LA, ed. Biomaterials in Regenerative Medicine. IntechOpen; 2017. doi: 10.5772/ intechopen.69716.

9. Gholipourmalekabadi M, Bandehpour M, Mozafari $M$, Hashemi A, Ghanbarian H, Sameni M, et al. Decellularized human amniotic membrane: more is needed for an efficient dressing for protection of burns against antibiotic-resistant bacteria isolated from burn patients. Burns. 2015;41(7):148897. doi: 10.1016/j.burns.2015.04.015.

10. Herndon DN, Branski LK. Contemporary methods allowing for safe and convenient use of amniotic membrane as a biologic wound dressing for burns. Ann Plast Surg. 2017;78(2 Suppl 1):S9-S10. doi: 10.1097/sap.0000000000000979.

11. Purpura V, Bondioli E, Cunningham EJ, De Luca G, Capirossi D, Nigrisoli E, et al. The development of a decellularized extracellular matrix-based biomaterial scaffold derived from human foreskin for the purpose of foreskin reconstruction in circumcised males. J Tissue Eng. 2018;9:2041731418812613. doi: $10.1177 / 2041731418812613$.

12. Zammit D, Kanevsky J, Meng FY, Dionisopoulos T. Meshed acellular dermal matrix: technique and application in implant based breast reconstruction. Plast Aesthet Res. 2016;3:254-6. doi: 10.20517/2347-9264.2015.128.

13. Li N, LiY, Gong D, Xia C, Liu X, Xu Z. Efficient decellularization for bovine pericardium with extracellular matrix preservation and good biocompatibility. Interact Cardiovasc Thorac Surg. 2018;26(5):768-76. doi: 10.1093/icvts/ivx416.

14. Talreja DR, Edwards WD, Danielson GK, Schaff HV, Tajik AJ, Tazelaar HD, et al. Constrictive pericarditis in 26 patients with histologically normal pericardial thickness. Circulation. 2003;108(15):1852-7. doi: 10.1161/01. cir.0000087606.18453.fd.

15. Mogaldea A, Theodoridis K, Goecke T, Tudorache I, Haverich A, Cebotari S, et al. Assessment of cytocompatibility and mechanical properties of detergent-decellularized ovine pericardial tissue. Int J Artif Organs. 2019;42(11):628-35. doi: 10.1177/0391398819850583.

16. Ishihara $\mathrm{T}$, Ferrans VJ, Jones $\mathrm{M}$, Boyce SW, Kawanami $\mathrm{O}$, Roberts WC. Histologic and ultrastructural features of normal human parietal pericardium. Am J Cardiol. 1980;46(5):74453. doi: 10.1016/0002-9149(80)90424-5.

17. Parízek J, Husek Z, Měricka P, Téra J, Němecek S, Spacek J, et al. Ovine pericardium: a new material for duraplasty. J Neurosurg. 1996;84(3):508-13. doi: 10.3171/jns.1996.84.3.0508.

18. Limpert JN, Desai AR, Kumpf AL, Fallucco MA, Aridge DL. Repair of abdominal wall defects with bovine pericardium. Am J Surg. 2009;198(5):e60-5. doi: 10.1016/j. amjsurg.2009.01.027.

19. Ayala P, Dai E, Hawes M, Liu L, Chaudhuri O, Haller CA, et al. Evaluation of a bioengineered construct for tissue engineering applications. J Biomed Mater Res B Appl Biomater. 2018;106(6):2345-54. doi: 10.1002/jbm.b.34042.

20. Abbas Khan MA, Chipp E, Hardwicke J, Srinivasan K, Shaw S, Rayatt $\mathrm{S}$. The use of Dermal Regeneration Template (Integra ${ }^{\circledR}$ ) for reconstruction of a large full-thickness scalp and calvarial defect with exposed dura. J Plast Reconstr Aesthet Surg. 2010;63(12):2168-71. doi: 10.1016/j.bjps.2010.03.017.

21. Choe JA, Jana S, Tefft BJ, Hennessy RS, Go J, Morse D, et al. Biomaterial characterization of off-the-shelf decellularized porcine pericardial tissue for use in prosthetic valvular applications. J Tissue Eng Regen Med. 2018;12(7):1608-20. doi: 10.1002/term.2686.

22. Feldman AT, Wolfe D. Tissue processing and hematoxylin and eosin staining. Methods Mol Biol. 2014;1180:31-43. doi: 10.1007/978-1-4939-1050-2_3.

23. Fischer $\mathrm{AH}$, Jacobson KA, Rose J, Zeller R. Hematoxylin and eosin staining of tissue and cell sections. CSH Protoc. 2008;2008:pdb.prot4986. doi: 10.1101/pdb.prot4986.

24. Oswal D, Korossis S, Mirsadraee S, Wilcox H, Watterson K, Fisher J, et al. Biomechanical characterization of decellularized and cross-linked bovine pericardium. J Heart Valve Dis. 2007;16(2):165-74.

25. Liuhanen S, Sallisalmi M, Pettilä V, Oksala N, Tenhunen J. Indirect measurement of the vascular endothelial glycocalyx layer thickness in human submucosal capillaries with a plug-in for ImageJ. Comput Methods Programs Biomed. 
2013;110(1):38-47. doi: 10.1016/j.cmpb.2012.10.019.

26. Karimpour Malekshah A, Talebpour Amiri F, Ghaffari E, Alizadeh A, Jamalpour Z, Mirhosseini M, et al. Growth and chondrogenic differentiation of mesenchymal stem cells derived from human adipose tissue on chitosan scaffolds. Journal of Babol University of Medical Sciences. 2016;18(9):32-8. doi: 10.22088/jbums.18.9.32.

27. Alizadeh A, Altarihi T, Dashtnavard $\mathrm{H}$. The influence of lithium chloride on induction of bone marrow stromal cells into neuronal phenotype. Daneshvar Medicine. 2009;16(79):51-6. [Persian].

28. Eftekharzadeh $M$, Nobakht $M$, Alizadeh $A$, Soleimani M, Hajghasem M, Kordestani Shargh B, et al. The effect of intrathecal delivery of bone marrow stromal cells on hippocampal neurons in rat model of Alzheimer's disease. Iran J Basic Med Sci. 2015;18(5):520-5.

29. Rezakhani L, Khazaei MR, Ghanbari A, Khazaei M. Crab shell extract induces prostate cancer cell line (LNcap) apoptosis and decreases nitric oxide secretion. Cell J. 2017;19(2):231-7. doi: 10.22074/cellj.2016.4879.

30. Chang Y, Tsai CC, Liang HC, Sung HW. In vivo evaluation of cellular and acellular bovine pericardia fixed with a naturally occurring crosslinking agent (genipin). Biomaterials. 2002;23(12):2447-57. doi: 10.1016/s0142-9612(01)00379-9.

31. de Rigal J, Escoffier C, Querleux B, Faivre B, Agache P, Lévêque JL. Assessment of aging of the human skin by in vivo ultrasonic imaging. J Invest Dermatol. 1989;93(5):621-5. doi: 10.1111/1523-1747.ep12319741.

32. Dua HS, Azuara-Blanco A. Amniotic membrane transplantation. Br J Ophthalmol. 1999;83(6):748-52. doi: 10.1136/bjo.83.6.748.

33. Gupta A, Kedige SD, Jain K. Amnion and chorion membranes: potential stem cell reservoir with wide applications in periodontics. Int J Biomater. 2015;2015:274082. doi: 10.1155/2015/274082.

34. Wilshaw SP, Kearney JN, Fisher J, Ingham E. Production of an acellular amniotic membrane matrix for use in tissue engineering. Tissue Eng. 2006;12(8):2117-29. doi: 10.1089/ ten.2006.12.2117.

35. Gálvez-Montón C, Fernandez-Figueras MT, Martí M, SolerBotija C, Roura S, Perea-Gil I, et al. Neoinnervation and neovascularization of acellular pericardial-derived scaffolds in myocardial infarcts. Stem Cell Res Ther. 2015;6(1):108. doi: 10.1186/s13287-015-0101-6.

36. Gholipourmalekabadi M, Sameni M, Radenkovic D, Mozafari M, Mossahebi-Mohammadi M, Seifalian A. Decellularized human amniotic membrane: how viable is it as a delivery system for human adipose tissue-derived stromal cells? Cell Prolif. 2016;49(1):115-21. doi: 10.1111/cpr.12240.

37. Gilbert TW, Sellaro TL, Badylak SF. Decellularization of tissues and organs. Biomaterials. 2006;27(19):3675-83. doi: 10.1016/j.biomaterials.2006.02.014.

38. Alizadeh M, Rezakhani L, Soleimannejad M, Sharifi E, Anjomshoa M, Alizadeh A. Evaluation of vacuum washing in the removal of SDS from decellularized bovine pericardium: method and device description. Heliyon. 2019;5(8):e02253. doi: 10.1016/j.heliyon.2019.e02253. 